\title{
Examining the efficacy, safety, and patient acceptability of the combined contraceptive vaginal ring (NuvaRing ${ }^{\circledR}$ )
}

This article was published in the following Dove Press journal:

International Journal of Women's Health

II November 2010

Number of times this article has been viewed

\section{Devorah R Wieder \\ Lynn Pattimakiel}

Center for Specialized Women's Health, Ob/Gyn and Women's Health Institute, Cleveland Clinic Foundation, Cleveland, OH, USA
Correspondence: Devorah R Wieder $\mathrm{Ob} / \mathrm{Gyn}$ and Women's Health Institute, Cleveland Clinic Foundation, 9500 Euclid Ave/A I0, Cleveland, OH 44195, USA

Tel +l 2I6-444-4645

Fax + I 216-445-1012

Email wiederd@ccf.org
Abstract: The contraceptive vaginal ring is a novel contraceptive method that offers unique advantages. Intravaginal delivery of both estrogen and progesterone allows continuous release of medication, resulting in lower systemic levels. The use of long-term combined hormonal contraception enables improved cycle control compared with progesterone-only methods. The indications and usage of the NuvaRing ${ }^{\circledR}$ are described along with the efficacy, tolerability, and safety. Overall, the contraceptive vaginal ring appears to be very effective, with a favorable side-effect profile, and is highly acceptable to most patients.

Keywords: vaginal contraception, vaginal ring, hormonal contraception, contraceptive agents, contraceptive device, etonogestrel, ethinyl estradiol, NuvaRing

\section{Introduction}

An ideal contraceptive would be highly effective, discreet, easy, and painless to use, and require no intervention by medical personnel. The method should have reversible effects and cause minimal interference with daily life and bodily functions. The drug should have high bioavailability, have low variability in serum levels, and cause minimal interference with other medications. ${ }^{1}$

The vaginal ring meets many of these criteria as the avoidance of first-pass metabolism by the liver enables lower dosing with continuous release and sustained levels of medication. The highly vascular nature of the vaginal mucosa, coupled with low sensitivity to foreign bodies, also contributes to the utility of vaginal administration. Single application by the user allows the convenience of long-term dosing and thus increased patient compliance. Avoidance of the fluctuations in hormone levels resulting from daily pill ingestion decreases side effects and may also improve compliance.

While long-acting forms of progesterone-only contraception have long been available, the lack of estrogen supplementation often results in increased rates of unscheduled bleeding. For many years, combined hormonal contraception including both estrogen and progesterone was available only in pill form. This method requires daily intake, with a common complaint of nausea as a side effect. In addition, intestinal absorption was unreliable due to multiple causes including interuser variation, vomiting, drug - drug interactions, and decreased intestinal absorption. Recently, combined hormonal contraception has become available in injection, transdermal patch, and now vaginal rings. 


\section{The NuvaRing ${ }^{\circledR}$}

Several vaginal contraception rings have been developed worldwide since the 1960s. These include progesteroneonly formulations in various sizes and shapes. Approved by the Food and Drug Administration in 2001, the NuvaRing ${ }^{\circledR}$ (Organon, Kenilworth, New Jersey) is a nonbiodegradable, latex-free, flexible, transparent, colorless, combined contraceptive vaginal ring composed of ethylene vinyl acetate copolymers and magnesium stearate. The ring contains $2.7 \mathrm{mg}$ of ethinyl estradiol (EE) and $11.7 \mathrm{mg}$ of etonogestrel. After placement in the vagina, each ring releases on average $0.015 \mathrm{mg} /$ day of EE and $0.120 \mathrm{mg} /$ day of etonogestrel over a 3-week period of use.

\section{Indications and contraindications for use}

The NuvaRing is indicated for prevention of pregnancy; however, additional benefits include improved cycle control and reduction in menorrhagia and dysmenorrhea. A report on the clinical use of the ring reveals no idealized patient for whom it is particularly suited, rather acceptability is high among younger and older reproductive-age women regardless of parity. ${ }^{2}$ Absolute contraindication to the NuvaRing relate mostly to the presence of estrogen (Table 1) and include history of cardiovascular events or venous thromboembolism (VTE), advanced hypertension or diabetes, liver disease or headaches with neurological manifestations, and smokers

Table I Patient considerations with the combined vaginal contraceptive ring

Contraindications
History of cardiovascular events
Venous thromboembolism
Advanced hypertension or diabetes
Liver disease
Headaches with neurological manifestations
Smokers older than 35 years of age
Women with known or suspected breast, endometrial, vaginal,
or cervical cancer
Undiagnosed abnormal vaginal bleeding
Additional counseling may be required for women with:
Personal history of benign breast disease
Family history of breast cancer
Diabetes, hyperlipidemia, hypertension
Migraine
Depression
Gallbladder, liver, heart, or kidney disease
Smokers younger than 35 years of age
Close surveillance needed in patients with:
History of vaginal irritation
Uterovaginal prolapse
Severe constipation
History of toxic shock syndrome

older than 35 years of age. The ring should not be used in women with known or suspected breast, endometrial, vaginal, or cervical cancer, or undiagnosed abnormal vaginal bleeding. Additional counseling may be required in women with personal history of benign breast disease, family history of breast cancer, diabetes, hyperlipidemia, hypertension, migraine, depression, or gallbladder, liver, heart, or kidney disease, and in those who smoke cigarettes. Estrogen-containing contraception should not be initiated within 30 days prior to a planned surgery, but need not be discontinued.

In addition, close surveillance may be needed in patients with history of vaginal irritation, uterovaginal prolapse, severe constipation, and history of toxic shock syndrome.

\section{Use of the NuvaRing}

The NuvaRing is inserted by the patient herself and is to remain in place for 3 weeks, followed by a 1-week ring-free period. Subsequently, a new ring is placed and the cycle is repeated. The ring is compressed into a more linear shape by the user and then placed high in the vagina, where it resumes a ring shape. The ring does not need to be precisely positioned inside the vagina.

An in vivo study using magnetic resonance imaging was conducted to establish the anatomic location of the ring in a nulliparous and a multiparous woman. ${ }^{3}$ The ring was found to lie above the urogenital diaphragm, surrounding the cervix, and was slightly compressed by the vaginal walls to form an ovoid shape. Of note, there was no displacement of the urethra with ring use. After ambulation, the ring was noted to move cephalad, with a more pronounced change in the nullipara (Figure 1).

Withdrawal bleeding is to be expected within 2-3 days of removal of the ring and may still continue past the proscribed 7 -day ring-free period. The new ring must be inserted 1 week after the removal of the prior ring to maintain contraceptive efficacy. Ideally, the NuvaRing should be inserted on cycle day 1. If inserted later, a backup method of contraception should be used for the first 7 days of ring use. The ring can be inserted within 5 days of a first trimester abortion or miscarriage, and beyond this point, backup contraception is required. The ring may be removed for up to 3 hours without loss of efficacy. If the ring has been removed for more than this time during the first or second week of use, backup contraception is required. If the ring is left out during the third week of use, it can be replaced by a new ring with backup contraception or left out for the usual 1-week period with subsequent replacement. If left in for more than 4 weeks, the ring should be removed for 7 days or replaced, 

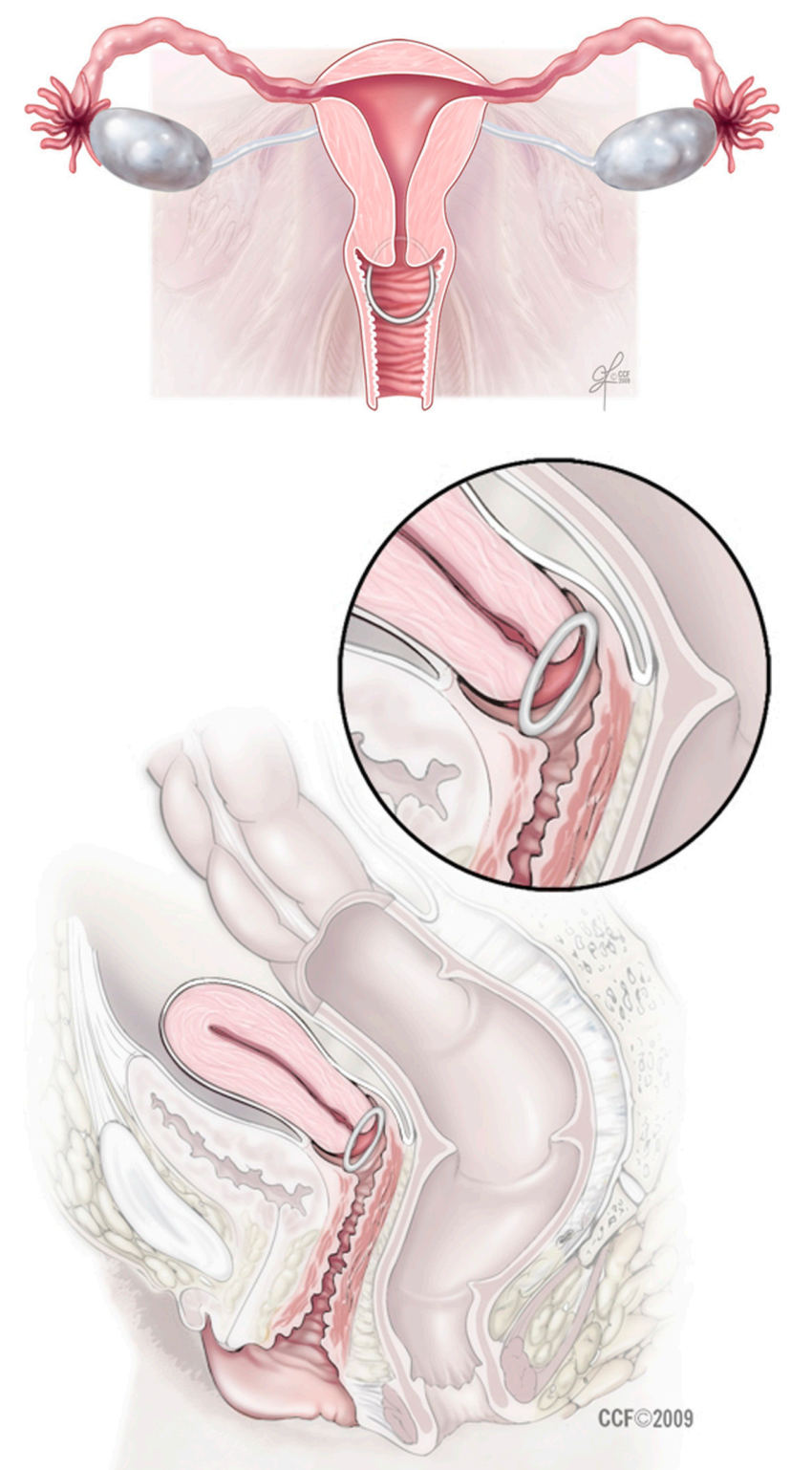

Figure I The contraceptive vaginal ring is positioned high in the vagina.

with backup contraception use required until 7 days after the next ring was placed.

As was common with combined oral contraception (COC), deviations from standard use including continuous use of the NuvaRing for suppression of menses are often suggested by gynecologists to decrease menorrhagia, to decrease dysmenorrhea, or for patient convenience. Common sense would advise similar caveats as for COCs regarding balancing the length of menstrual suppression with increasing risk of irregular bleeding as use is extended. Shortening the ring-free interval may be appropriate for certain patients as will be discussed below.

\section{Efficacy \\ Pregnancy rates}

Pregnancy rates with the vaginal ring appear to be low. In phase 3 trials, the Pearl index was 0.65 pregnancies per 100 woman-years of use; however, $50 \%$ of the six pregnancies occurred in protocol violators. ${ }^{4}$ In a large, international, multicenter observational trial, the Pearl index was $1.18 .{ }^{5}$ In other studies, comparing the vaginal ring with $\mathrm{COC}$, results ranged from no pregnancies in either group ${ }^{6}$ to a Pearl index of 0.25 compared with 0.99 with $\mathrm{COC}$, among those in the intention-to-treat groups. ${ }^{7}$ Cited pregnancy rates for 1-year use of COC, NuvaRing, and the transdermal patch are all set at $8 \%$ for typical use and $0.3 \%$ for perfect use. Given low rates of pregnancy on COC, it is likely that the studies needed to prove superior efficacy of methods with the promise of greater compliance over COC would not be feasible. $^{8}$

\section{Mechanism of action}

As with COC, the chief mechanism of action is the inhibition of gonadotropins and prevention of ovulation along with effects on cervical mucus and endometrial histology. Clinical studies show that the maximum serum concentration of EE is attained after 2-3 days, whereas the maximum level of etonogestrel is attained after 1 week. Serum levels then decrease progressively and linearly. ${ }^{9}$ Total exposure to estrogen (area under the curve) was 3.4 times higher than that for the NuvaRing and 1.6 times higher than that for a $30 \mu \mathrm{g}$ EE COC.

While serum levels are low, the contribution of the "uterine first pass" effect is unknown. When uterine levels were studied in hysterectomy specimens in women pretreated with either a $20 \mu \mathrm{g}$ EE COC or the NuvaRing, uterine hormone levels were comparable in the upper and mid myometrium, and the cervical region. Conversely, endometrial concentrations of estrogen were higher in the COC group. These results favor continuous dosing with the vaginal ring as the driving force behind improved cycle control compared with users of lowdose COC. ${ }^{10}$

\section{Prevention of ovulation}

Complete inhibition of ovulation as measured by follicle formulation and luteinizing hormone (LH) and progesterone levels was found during the typical 3 weeks of use and for 2 additional weeks. ${ }^{11}$ The endometrium was found to be thinned in all subjects and was comparable to the COC group. Serum follicle-stimulating hormone and $17 \beta$-estradiol levels 
were highest during the first week of use, reflecting innate hormonal activity prior to insertion.

The same investigators tested ovulation suppression under conditions of atypical use as well, with notable findings. ${ }^{12}$ Following a typical-use cycle, insertion for as few as 3 days will delay ovulation. In addition, delay of reinsertion until follicles reached $13 \mathrm{~mm}$ will still inhibit ovulation, even with these larger follicles. In this group, 50\% of women required more than 4 days until follicles reached this threshold and none subsequently ovulated. Despite the development of follicles when reinsertion is delayed, the LH surge is likely still inhibited once the ring is inserted. Subsequent follow-up in the next untreated cycle revealed that ovulation occurred in 27 of 29 women, highlighting the rapid return to fertility after discontinuation of this method.

In women with documented ovulation on cycle days 9-12, follicle growth was not suppressed by the NuvaRing compared with a $30 \mu \mathrm{g}$ EE COC. ${ }^{13}$ If escape ovulation occurs in these women, pregnancy may still be prevented due to effects on cervical mucus and endometrial histology. If ovulation does not occur, these larger follicles may develop into cysts. These investigators, thus, recommended reducing the treatment-free interval to 5 days or skipping it completely in women with ovulation prior to cycle day 12 or if the entire cycle length is less than 26 days.

\section{Factors that might modify efficacy}

Multiple factors that might be presumed to affect the efficacy of the NuvaRing have been studied, with overall minimal interactions. The use of a nonoxynyol-9-containing spermicide ${ }^{14}$ or tampon co-usage ${ }^{15}$ was not found to affect hormone levels, efficacy, or tolerability. The use of antimycotic medications was found to increase systemic hormone levels, with lower drug levels present in the ring when assayed after removal. This effect was more pronounced when multiple doses of suppositories were used compared with comparable doses of cream; however, these changes were not expected to influence efficacy or tolerability. ${ }^{16}$ No change in serum concentration of hormones was noted during the usage of oral amoxicillin or doxycycline. ${ }^{17}$ Of note, unlike COCs and the transdermal patch, body weight does not appear to influence efficacy. ${ }^{18}$

\section{Cycle control}

Predictable patterns of bleeding while on hormonal contraception are highly desirable to patients, with consistent monthly scheduled bleeding and low rates of unscheduled bleeding. One of the unique aspects of the ring is the excellent cycle control afforded despite overall low serum levels of estrogen. The ring releases $15 \mu \mathrm{g}$ of EE daily, and comparable low-dose COCs are well known to result in patterns of breakthrough bleeding. In phase 3 trials, cycle control was found to be excellent, with irregular bleeding noted in only $2.6 \%-6.4 \%$ of cycles. $^{4}$

In trials comparing the NuvaRing with various $30 \mu \mathrm{g} \mathrm{EE}$ COCs, the ring was noted to have lower incidence of breakthrough bleeding even in the first cycle. ${ }^{19,20}$ In addition, there was an increased rate of scheduled bleeding and a decreased rate of late-withdrawal bleeding.

Withdrawal bleeding provides monthly reassurance to patients regarding absence of pregnancy. In the phase 2 trial, withdrawal bleeding was only absent in $0.6 \%-2.1 \%$ of cycles. ${ }^{4}$ Early-withdrawal bleeding, occurring prior to ring removal, was present in $5.4 \%-7.7 \%$ of cycles. Latewithdrawal bleeding that persisted past the 7-day ring-free period was noted in $20.4 \%-27.3 \%$ of cycles, but consisted mostly of spotting. As one in five women may experience this spotting, the importance of prompt reinsertion must be emphasized, given the possibility of escape ovulation if ring reinsertion is delayed.

\section{Extended use}

Continuous or extended use of combined hormonal contraception is often advised by gynecologists to decrease menorrhagia, dysmenorrhea, menstrual migraines, and premenstrual symptoms. Extended use with replacement of the ring every 21 days for 84 continuous days of use for 1 year resulted in increased rates of irregular bleeding during the first 4-month interval. Subsequently, there was small decrease in the number of scheduled bleeding days, with bleeding occurring on 15 of the 28 possible bleeding days. ${ }^{21}$ Only $4 \%$ of women who discontinued the vaginal ring cited this pattern of bleeding as the cause. A similar trial evaluated 28-, 49-, 91-, and 364-day cycles and noted that the median number of scheduled bleeding days increased with longer cycle duration. There was an accompanying increase in the days of unscheduled bleeding, which was mostly spotting. ${ }^{22}$ Contraceptive efficacy remained similar with reduced dysmenorrhea, menstrual migraine, and premenstrual symptoms with extended use. Patients reported higher satisfaction with shorter cycles; however, the trial did not evaluate satisfaction, especially in women with menorrhagia, who might tolerate a greater degree of spotting. Management of unscheduled bleeding while on an extended regimen was evaluated in women replacing the ring every 4 weeks for 6 months. ${ }^{23}$ Those women randomized to remove the ring for 4 days following 
5 days of continuous bleeding were noted to subsequently have absence of spotting on an increased number of days compared with those who kept the ring in place.

\section{Tolerability}

The side effects attributed to contraceptive use are varied and play a crucial role in determining continuation rates. Commonly reported side effects related to NuvaRing use are headache, vaginitis, weight gain, and nausea. ${ }^{24}$

Headaches were reported in $3.3 \%$ of ring users compared with $2.4 \%$ of those using a $30 \mu \mathrm{g}$ EE COC in a trial of 264 women. ${ }^{19}$ In noncomparative studies, headaches were reported by $5.5 \%-5.8 \%$ of ring users. ${ }^{5,24}$

Compared with COC users, ring users report increased rates of vulvovaginal complaints, such as discharge, vaginal irritation, vaginitis, and leukorrhea, ${ }^{25,26}$ and more women cited these concerns as the reason for discontinuation compared with COC users. ${ }^{5,26}$ In one of the observational studies, vaginitis symptoms were reported by $13.7 \%$ of women subjects. ${ }^{5}$

Most cases of vaginitis were due to candidal infection, ${ }^{26}$ and the most common strains all show high adherence to the ring. The in-vitro adherence of different yeasts was studied using isolates from vaginal exudates of patients with vulvovaginal candidiasis. Candida albicans adhered the least, followed by, adherence in increasing order, C. parapsilosis, Saccharomyces cerevisiae, C. tropicalis, and C. glabrata. ${ }^{27}$ Thus, the presence of recurrent yeast infection in women using vaginal rings may be characterized by infection with less common species.

Foreign body effects on the vaginal surface have not been evaluated with the NuvaRing but were studied in four other contraceptive vaginal rings: Nestorone ${ }^{\circledR}$ (Watson Pharmaceuticals, Inc- Corona, CA, USA) EE/Nestorone, EE/norethindrone acetate (over 4 months), and EE/norethindrone acetate (over 12 months). A total of $17.4 \%$ of inspections showed atypical conditions of the vaginal surface appearance, many being subtle. These findings included all ulcerations, abrasions, and ecchymoses. The majority of atypical conditions (83\%) disappeared by the next scheduled colposcopy despite continued ring use, indicating that the vaginal rings contribute little to clinically significant lesions. ${ }^{28}$

Varying results have been reported on the effect of the NuvaRing on body weight. Three studies comparing the NuvaRing and the oral contraceptives showed weight neutrality with the NuvaRing use..$^{19,20,26}$ In one study, a clinically significant decrease in body weight was noted in the NuvaRing group compared with the COC group. ${ }^{26}$
In another study, a clinically significant increase in body weight was noted in the COC group compared with the NuvaRing group, with an overall small mean change in body weight in both groups. ${ }^{19}$ In an observational study, body weight and body mass index remained stable on the NuvaRing group, with $86.9 \%$ of subjects experiencing no relevant change. ${ }^{25}$ In contrast, $6.1 \%$ of the ring users in an observational study reported a significant weight increase from baseline although perception of weight change was minimal. It is possible that modified eating behaviors due to fear of weight gain may have played a role in the results.

While nausea is one of the more frequently reported side effect of the NuvaRing use, the actual incidence appears to be lower compared with low-dose COC use, probably related to the avoidance of the gastrointestinal tract. In an observational study, nausea and gastrointestinal side effects were reported in $2.5 \%$ of subjects. This is also reflected by data from the comparative trials, with rates of $2.7 \%$ in ring users compared to $4 \%$ of those taking $30 \mathrm{mg} \mathrm{EE} / 150 \mathrm{mg}$ levonorgestrel (LNG). ${ }^{19,24}$

Nausea has also been reported with a vaginal ring releasing $20 \mu \mathrm{g} \mathrm{EE} / 1 \mathrm{mg}$ norethindrone acetate. The effects on nausea with different insertion regimens of this ring were studied. Transient nausea was seen following insertion of a new ring, lasting from 0.5 to 48 hours. The study concluded that the incidence of nausea was highest with bedtime insertion. Transient vomiting occurred in approximately $10 \%$ of women in the first 24 hours after first insertion of a new ring. Nausea decreased with early evening insertion, temporary removal during the first night, and overnight soaking of the ring in water before use. Incidence of nausea also decreased during the second cycle of each regimen. ${ }^{29}$

\section{Safety}

The use of the vaginal ring was not found to significantly affect blood pressure. No clinically relevant change from baseline was seen during observational trials or postmarketing surveillance in either diastolic or systolic blood pressure. ${ }^{5,25} \mathrm{In}$ a trial comparing COC and NuvaRing use, $\leq 4 \%$ of subjects in each treatment group experienced hypertension. ${ }^{26}$

No significant changes in cervical cytology have been attributed to NuvaRing use. In an observational trial, a total of $1.3 \%$ of subjects changed from normal cytology to low-grade squamous intraepithelial lesions and $0.4 \%$ of subjects changed to high-grade squamous intraepithelial lesion/carcinoma in situ. Normal shifts in cervical cytology 
may have been detected because of the frequent screening during the study. ${ }^{5}$

Development of VTE is of great concern with the use of combined hormonal contraceptive. While the absolute risk of VTE with the use of the contraceptive vaginal ring has not been established, cases have been reported during clinical trials. In comparative studies, single reports of deep vein thrombosis were seen, thought to be possibly related to the NuvaRing. ${ }^{19,26}$ One report of cerebral venous sinus thrombosis was seen with NuvaRing use. ${ }^{30} \mathrm{~A}$ case report by Voora and Vijayan ${ }^{31}$ identified development of a mesenteric vein thrombosis associated with intravaginal hormonal contraceptive use, 3 months after initiation in a 32-year-old nonsmoking female, with no risk factors or hypercoagulability. ${ }^{31}$

Both the NuvaRing and oral LNG/EE are associated with a minimal effect on hemostatic variables. Factor VII levels increased in the NuvaRing group and decreased in the LNG/EE group. Antithrombin activity and protein C activity were reported to be higher in the NuvaRing group. The anticoagulation and fibrinolytic activities were comparable between the NuvaRing and oral LNG/EE groups. Levels of tissue plasminogen activator decreased in both groups, but the reduction was smaller in the NuvaRing group. There were no significant differences in fibrin turnover between the treatment groups. ${ }^{32}$

The NuvaRing may represent an appropriate choice for contraception use in women at risk for developing diabetes mellitus or metabolic syndrome..$^{33}$ It has been shown to be a safe form of contraception in late-reproductive-age women with type 1 diabetes mellitus, as no clinically significant effect on carbohydrate metabolism was seen, compared with the control group of age-matched women with type 1 diabetes mellitus using no contraception. ${ }^{34}$ Also in a comparative study, insulin sensitivity significantly decreased during COC use and tended to increase during vaginal administration of hormonal contraceptives. ${ }^{33}$

Other comparative studies show similar results, reporting a lesser impact on carbohydrate metabolism compared with low-dose combined oral contraceptive use. A greater reduction in free androgen and dehydroepiandrosterone sulfate levels was seen with the ring use compared with pill treatment. The basal insulin resistance was slightly decreased, but a significant reduction in the insulin sensitivity index was found in women on pill therapy compared with those in the ring group $(P<0.035)$. Pancreatic $\beta$-cell function was not significantly altered with either treatment. ${ }^{35}$

In the study by Duijkers et al, ${ }^{36}$ no clinically relevant effects were seen on adrenal or thyroid function (free thyroxine) with both the NuvaRing and the oral contraceptive use. There was a significantly lower increase in concentrations of cortisol-binding globulin and total cortisol during the ring use compared with COC. In the comparative study by Cagnacci et al, ${ }^{33} \gamma$-glutamine transferase slightly increased in the oral group and slightly decreased in the vaginal group $(P=0.04)$.

The NuvaRing has been shown to have minimal effect on lipid profile, with no change seen in total cholesterol, highdensity lipoprotein (HDL) cholesterol, and low-density lipid cholesterol in observational trials. When the ring was compared with a combined oral contraceptive $(30 \mu \mathrm{g}$ EE $/ 150 \mu \mathrm{g}$ LNG), stable total cholesterol was found in both groups, along with increases in apolipoprotein B and triglycerides. In contrast to a decrease in $\mathrm{HDL}, \mathrm{HDL}_{2}$, and $\mathrm{HDL}_{3}$ levels in the $\mathrm{COC}$ group, $\mathrm{HDL}_{2}$ increased in NuvaRing group. Apolipoprotein A-1 levels increased in NuvaRing group but decreased in COC group, and lipoprotein(a) decreased in both groups. Sex-hormone-binding globulin increased markedly more with NuvaRing, whereas corticosteroid-binding globulin levels increased to a lesser degree. These changes may reflect the lower androgenicity of etonogestrel compared with levonorgestrel. ${ }^{37}$

The effect of the contraceptive vaginal ring on bone mineral density (BMD) was studied in an open-label multicenter cohort of premenopausal women and nonhormonal contraceptive users. There were no changes from baseline $z$ scores in the contraceptive ring group in both the spine and the femoral necks. The control group BMD showed an increase from baseline, resulting in a significant difference $(P<0.0001)$ between the two groups at 24 months. Therefore, there was a decreased acquisition of peak bone mass in the contraceptive ring group. The study concluded that the use of contraceptive ring for 2 years did not produce changes in BMD in healthy premenopausal women, as the differences were within 1 standard deviation of one another. There was no assessment of fracture risk, an outcome with greater clinical relevance. ${ }^{38,39}$

There is approximately $85 \%$ of remaining EE load after the NuvaRing's use. An assessment was performed on the potential environmental exposure in landfills from discarding the hormonal ring in household waste. This study concluded that EE does not have a high mobility in landfills and soils. Column experiments estimate the duration of 40 years before EE leaches from a column of $1 \mathrm{~m}$ of landfill material. This makes emission from landfills negligible and reduces potential for groundwater contamination..$^{40}$ 
Ease of use is one of the features of the NuvaRing that increase acceptability. Women can generally be reassured that as long as the vaginal ring stays in place, it has been positioned correct. The solitary exception is intravesicular placement. Currently, there are two case reports of accidental self-insertion of the NuvaRing into the bladder with subsequent symptoms of urinary urgency, frequency, and pelvic pain until the ring was located and removed. ${ }^{41,42}$ Insertion instructions should, thus, be reviewed with the patient and insertion demonstrated in the office if necessary. Any unusual or persistent complaints in users of vaginal rings should be carefully investigated.

\section{Patient acceptability}

Patient acceptability of any contraceptive method involves multiple factors, including ease of use, side-effect profile, and efficacy. As in all clinical interventions, realistic expectations and careful patient counseling are vital components in improving compliance. An additional hurdle with the use of a contraceptive vaginal ring is acceptance of the new route of administration.

\section{Compliance and ease of use}

In phase 3 trials, compliance was reported in $90.8 \%$ of cycles, with a prolonged ring-free interval in $4.1 \%$ of women. ${ }^{42}$ During the trial, $29.6 \%$ of women discontinued the ring, most during the first 3-4 cycles. Reasons cited were device related, including foreign body sensation, discomfort with coitus, and ring expulsion rather than irregular bleeding. Insertion and removal were felt to be simple. Overall, 96\% of women stated they liked the ring and $98 \%$ would recommend it to others.

In an international multicenter trial, the rate of ring removal was $1.2 \%$ in the United States compared with $0.28 \%$ in Europe. ${ }^{5}$ Of note, the contraceptive failure rate was also higher in the United States compared with Europe.

In a large trial of women randomized to the NuvaRing or $30 \mathrm{mg} E \mathrm{E} / 150 \mu \mathrm{g}$ of LNG, the ring-free period was prolonged in $6.6 \%$ of cycles compared with $2.9 \%$ cycles with a prolonged pill-free period. ${ }^{26}$

\section{Satisfaction rates}

In a large administrative claims database, the transdermal patch and transvaginal ring were 1.6 and 1.7 times more likely to be discontinued at 3 months than COC..$^{43}$ This study does not detail whether desire for pregnancy, adverse events, or cost factors contributed to discontinuation.

In contrast, telephone callback rates were the lowest with the ring compared with the transdermal patch and COC in a population of previous COC users, and most complaints were related to ring expulsion or partner complaints. ${ }^{44}$

User acceptability was studied in the United States, Canada, Germany, Austria, Norway, Sweden, Denmark, Finland, France, the Netherlands, Belgium, Spain, the United Kingdom, and Israel. ${ }^{45}$ At entry, the COC was cited as the contraceptive of choice; however, after 3 cycles, $81 \%$ preferred the ring. The most commonly reported reason for dislike was that the ring was falling out. In past users of COC randomized to the NuvaRing or the transdermal patch, $70.6 \%$ desired to continue the NuvaRing and $21.6 \%$ desired to resume COC use. ${ }^{6}$

\section{Sexual activity}

Evidence for a change in libido with the use of COC is equivocal. Vaginal delivery of contraception, therefore, requires scrutiny regarding effects on sexual activity. In women randomized to NuvaRing or a COC containing desogestrel and $30 \mu \mathrm{g}$ EE, improvement in sexual function across several spheres was noted in both groups. ${ }^{46}$ The NuvaRing group had increased rates of sexual fantasy and sexual frequency, and their partners reported increase in sexual interest, complicity, and sexual fantasy. While a placebo group using an inert ring was not included, the authors speculate that the presence of a foreign body may be stimulating to both partners and in addition serve as a reminder of contraceptive efficacy, further decreasing anxiety during intercourse.

\section{Conclusion}

The contraceptive vaginal ring, thus, represents an efficacious and well-tolerated means of hormonal contraception. Longterm, continuous release via vaginal administration confers unique benefits with this method. The ring has a favorable adverse event and side-effect profile. Individualized patient assessment to identify appropriate users and careful counseling to ensure correct use and create realistic expectations can improve compliance rates with this novel contraceptive.

\section{Disclosure}

The authors report no conflicts of interest in this work.

\section{References}

1. Alexander NJ, Baker E, Miller L, Zampaglione E. Why consider vaginal drug administration? Fertil Steril. 2004;82:1-12.

2. Merki-Feld GS, Hund M. Clinical experience with NuvaRing in daily practice in Switzerland: cycle control and acceptability among women of all reproductive ages. Eur J Contracept Reprod Health Care. 2007;12:240-247.

3. Barnhart KT, Timbers K, Pretorius ES, Lin K, Shaunik A. In vivo assessment of NuvaRing placement. Contraception. 2005;72:196-199. 
4. Roumen FJ, Apter D, Mulders TM, Dieben TO. Efficacy, tolerability and acceptability of a novel contraceptive vaginal ring releasing etonogestrel and ethinyl oestradiol. Hum Reprod. 2001;16:469-475.

5. Dieben TO, Roumen FJ, Apter D. Efficacy, cycle control, and user acceptability of a novel combined contraceptive vaginal ring. Obstet Gynecol. 2002;100:585-593.

6. Creinin MD, Meyn LA, Borgatta L, et al. Multicenter comparison of the contraceptive ring and patch. Obstet Gynecol. 2008;111: 267-277.

7. Ahrendt HJ, Nisand I, Bastianelli C, et al. Efficacy, acceptability and tolerability of the combined contraceptive ring, NuvaRing, compared with an oral contraceptive containing 30 microg of ethinyl estradiol and $3 \mathrm{mg}$ of drospirenone. Contraception. 2006;74:451-457.

8. Hatcher RA, Trussell J, Nelson AL, Cates W Jr, Stewart F. Contraceptive Technology. New York: Ardent Media; 2007.

9. Timmer CJ, Mulders TM. Pharmacokinetics of etonogestrel and ethinylestradiol released from a combined contraceptive vaginal ring. Clin Pharmacokinet. 2000;39:233-242.

10. Roumen FJ, Dieben TO. Comparison of uterine concentrations of ethinyl estradiol and etonogestrel after use of a contraceptive vaginal ring and an oral contraceptive. Fertil Steril. 2006;85:57-62.

11. Mulders TM, Dieben TO. Use of the novel combined contraceptive vaginal ring NuvaRing for ovulation inhibition. Fertil Steril. 2001; 75:865-870

12. Mulders TM, Dieben TO, Bennink HJ. Ovarian function with a novel combined contraceptive vaginal ring. Hum Reprod. 2002; 17:2594-2599.

13. Duijkers IJ, Verhoeven CH, Dieben TO, Klipping C. Follicular growth during contraceptive pill or vaginal ring treatment depends on the day of ovulation in the pretreatment cycle. Hum Reprod. 2004;19:2674-2679.

14. Haring T, Mulders TM. The combined contraceptive ring NuvaRing and spermicide co-medication. Contraception. 2003;67: 271-272.

15. Verhoeven $\mathrm{CH}$, Dieben TO. The combined contraceptive vaginal ring, NuvaRing, and tampon co-usage. Contraception. 2004;69: 197-199.

16. Verhoeven $\mathrm{CH}$, van den Heuvel MW, Mulders TM, Dieben TO. The contraceptive vaginal ring, NuvaRing, and antimycotic co-medication. Contraception. 2004;69:129-132.

17. Dogterom P, van den Heuvel MW, Thomsen T. Absence of pharmacokinetic interactions of the combined contraceptive vaginal ring NuvaRing with oral amoxicillin or doxycycline in two randomised trials. Clin Pharmacokinet. 2005;44:429-438.

18. Westhoff C. Higher body weight does not affect Nuvaring ${ }^{\circledR}$ 's efficacy. Obstet Gynecol 2005;105 Suppl 4:S56.

19. Bjarnadottir RI, Tuppurainen M, Killick SR. Comparison of cycle control with a combined contraceptive vaginal ring and oral levonorgestrel/ ethinyl estradiol. Am J Obstet Gynecol. 2002;186:389-395.

20. Milsom I, Lete I, Bjertnaes A, et al. Effects on cycle control and bodyweight of the combined contraceptive ring, NuvaRing, versus an oral contraceptive containing 30 microg ethinyl estradiol and $3 \mathrm{mg}$ drospirenone. Hum Reprod. 2006;21:2304-2311.

21. Barreiros FA, Guazzelli CA, de Araujo FF, Barbosa R. Bleeding patterns of women using extended regimens of the contraceptive vaginal ring. Contraception. 2007;75:204-208.

22. Miller L, Verhoeven CH, Hout J. Extended regimens of the contraceptive vaginal ring: a randomized trial. Obstet Gynecol. 2005;106: 473-482.

23. Sulak PJ, Smith V, Coffee A, Witt I, Kuehl AL, Kuehl TJ. Frequency and management of breakthrough bleeding with continuous use of the transvaginal contraceptive ring. Obstet Gynecol. 2008;112: 563-571.

24. Bruni V, Pontello V, Luisi S, Petraglia F. An open-label, multicentre trial to evaluate the vaginal bleeding pattern of the combined contraceptive vaginal ring NuvaRing. Eur J Obstet Gynecol Reprod Biol. 2008;139:65-71.
25. Brucker C, Karck U, Merkle E. Cycle control, tolerability, efficacy and acceptability of the vaginal contraceptive ring, NuvaRing: results of clinical experience in Germany. Eur J Contracept Reprod Health Care. 2008;13:31-38.

26. Oddsson K, Leifels-Fischer B, de Melo NR, et al. Efficacy and safety of a contraceptive vaginal ring (NuvaRing) compared with a combined oral contraceptive: a 1-year randomized trial. Contraception. 2005;71:176-182.

27. Camacho DP, Consolaro ME, Patussi EV, Donatti L, Gasparetto A, Svidzinski TI. Vaginal yeast adherence to the combined contraceptive vaginal ring (CCVR). Contraception. 2007;76:439-443.

28. Fraser IS, Lacarra M, Mishell DR, et al. Vaginal epithelial surface appearances in women using vaginal rings for contraception. Contraception. 2000;61:131-138.

29. Weisberg E, Fraser IS, Lacarra M, Mishell DR Jr, Jackanicz T. Effect of different insertion regimens on side effects with a combination contraceptive vaginal ring. Contraception. 1997;56:233-239.

30. Roumen FJ, op ten Berg MM, Hoomans EH. The combined contraceptive vaginal ring (NuvaRing): First experience in daily clinical practice in the Netherlands. Eur J Contracept Reprod Health Care. 2006;11:14-22.

31. Voora D, Vijayan A. Mesenteric vein thrombosis associated with intravaginal contraceptives: a case report and review of the literature. J Thromb Thrombolysis. 2003;15:105-108.

32. Magnusdottir EM, Bjarnadottir RI, Onundarson PT, et al. The contraceptive vaginal ring (NuvaRing) and hemostasis: a comparative study. Contraception. 2004;69:461-467.

33. Cagnacci A, Ferrari S, Tirelli A, Zanin R, Volpe A. Route of administration of contraceptives containing desogestrel/etonorgestrel and insulin sensitivity: a prospective randomized study. Contraception. 2009;80:34-39.

34. Grigoryan OR, Grodnitskaya EE, Andreeva EN, Chebotnikova TV, Melnichenko GA. Use of the NuvaRing hormone-releasing system in late reproductive-age women with type 1 diabetes mellitus. Gynecol Endocrinol. 2008;24:99-104.

35. Elkind-Hirsch KE, Darensbourg C, Ogden B, Ogden LF, Hindelang $\mathrm{P}$. Contraceptive vaginal ring use for women has less adverse metabolic effects than an oral contraceptive. Contraception. 2007;76: 348-356

36. Duijkers I, Killick S, Bigrigg A, Dieben TO. A comparative study on the effects of a contraceptive vaginal ring NuvaRing and an oral contraceptive on carbohydrate metabolism and adrenal and thyroid function. Eur J Contracept Reprod Health Care. 2004;9:131-140.

37. Tuppurainen M, Klimscheffskij R, Venhola M, Dieben TO. The combined contraceptive vaginal ring (NuvaRing) and lipid metabolism: a comparative study. Contraception. 2004;69:389-394.

38. Martins SL, Curtis KM, Glasier AF. Combined hormonal contraception and bone health: a systematic review. Contraception. 2006; 73:445-469

39. Massai R, Makarainen L, Kuukankorpi A, Klipping C, Duijkers I, Dieben $\mathrm{T}$. The combined contraceptive vaginal ring and bone mineral density in healthy pre-menopausal women. Hum Reprod. 2005;20: 2764-2768.

40. Geurts MG, de Boer W, de Graaf JS, van Ginkel CG. Environmental exposure assessment of ethinyl estradiol (EE) from a combined hormonal vaginal contraceptive ring after disposal; leaching from landfills. Sci Total Environ. 2007;377:366-370.

41. Tarragón Gabarró S, Checa Vizcaíno MA, Arango Toro O. Accidental introduction of a contraceptive vaginal ring into the urinary bladder. Int Urogynecol J Pelvic Floor Dysfunct. 2009;20:1511-1513.

42. Teal SB, Craven WM. Inadvertent vesicular placement of a vaginal contraceptive ring presenting as persistent cystitis. Obstet Gynecol. 2006;107:470-472.

43. Murphy PA, Brixner D. Hormonal contraceptive discontinuation patterns according to formulation: investigation of associations in an administrative claims database. Contraception. 2008;77: 257-263. 
44. Victor I, Fink RA. Comparing patient telephone callback rates for different hormonal birth control delivery systems. Am J Ther. 2006; 13:507-512.

45. Novak A, de la Loge C, Abetz L, van der Meulen EA. The combined contraceptive vaginal ring, NuvaRing: an international study of user acceptability. Contraception. 2003;67:187-194.
46. Guida M, Di Spiezio Sardo A, Bramante S, et al. Effects of two types of hormonal contraception - oral versus intravaginal - on the sexual life of women and their partners. Hum Reprod. 2005;20:1100-1106.

International Journal of Women's Health

\section{Publish your work in this journal}

The International Journal of Women's Health is an international, peerreviewed open-access journal publishing original research, reports, reviews and commentaries on all aspects of women's healthcare including gynecology, obstetrics, and breast cancer. Subject areas include: Chronic conditions (migraine headaches, arthritis, osteoporosis);
Endocrine and autoimmune syndromes; Sexual and reproductive health; Psychological and psychosocial conditions. The manuscript management system is completely online and includes a very quick and fair peer-review system. Visit http://www.dovepress.com/ testimonials.php to read real quotes from published authors.

Submit your manuscript here: http://www.dovepress.com/international-journal-of-womens-health-journal 